\title{
Metodologias ativas: das concepções às práticas em distintos níveis de ensino
}

\author{
Active methodologies: from conceptions to practices in \\ different levels of teaching
}

\section{Metodologías activas: de las concepciones a las prácticas en distintos niveles de enseñanza}

\section{José Armando Valente ${ }^{[a]}[b]$, Maria Elizabeth Bianconcini de Almeida ${ }^{[b]}$, Alexandra Fogli Serpa Geraldini ${ }^{[b]^{*}}$}

\author{
[a] Universidade Estadual de Campinas (Unicamp), Campinas, SP, Brasil \\ [b] Pontifícia Universidade Católica de São Paulo (PUC-SP), São Paulo, SP, Brasil
}

\section{Resumo}

Este artigo foi desenvolvido com base no trabalho realizado a partir da disciplina Currículo, Tecnologias, Aprendizagem e os Desafios à Educação na Cultura Digital, ministrada durante o segundo semestre de 2016, no Programa de Pós-graduação em Educação: Currículo, da Pontifícia Universidade Católica de São Paulo (PUC-SP). Essa disciplina tinha como objetivo 
desenvolver práticas que explorassem o uso das Tecnologias Digitais de Informação e Comunicação (TDIC) e estudar as contribuições e limites que tais práticas oferecem ao desenvolvimento do currículo e à aprendizagem baseada nas metodologias ativas. Oito estudantes de mestrado e doutorado participaram dela e, como parte das atividades, cada um desenvolveu uma prática pedagógica com alunos do ensino básico ou superior, baseada em metodologias ativas com o uso das TDIC. Como produto dessa experiência, cada estudante produziu um texto reflexivo e uma narrativa digital, representando o processo de aprendizagem ao longo da disciplina. Os resultados do trabalho possibilitaram entender as diferentes concepções sobre metodologias ativas, bem como analisar as potencialidades destas metodologias para uso em diferentes níveis de ensino.

Palavras-chave: Prática pedagógica. Aprendizagem. Tecnologia educacional.

\section{Abstract}

This article was developed based on the work carried out from the course "Curriculum, technologies, learning, and the challenges to education in the digital culture" during the second semester of 2016 in the Graduate Program in Education: Curriculum, of the Pontifical Catholic University of São Paulo (PUC-SP). The purpose of this course was to develop practices that explore the use of digital information and communication technologies (DICT) and to study the contributions and limitations that such practices offer to curriculum development and learning based on active methodologies. Eight Master or Ph.D. students participated in this course. As part of the activities, each student developed a pedagogical practice with K12 or college pupils based on active methodologies using DICT. As a product of this experience each student produced a reflexive text and a digital narrative, representing the learning process throughout the course. The results of the work revealed the different conceptions of active methodologies, as well as the potential of these methodologies for use in various levels of education.

Keywords: Pedagogical practice. Learning. Educational technology. 


\section{Resumen}

Este artículo fue desarrollado con base en el trabajo realizado a partir de la disciplina "Currículo, tecnologías, aprendizaje y los desafíos a la educación en la cultura digital", realizada durante el segundo semestre de 2016 en el Programa de Postgrado en Educación: Currículo de la Pontificia Universidad Católica de São Paulo (PUC-SP). Esta disciplina tenía como objetivo desarrollar prácticas que explotaran el uso de las tecnologías digitales de información y comunicación (TDIC) y estudiar las contribuciones y límites que tales prácticas ofrecen al desarrollo del currículo y al aprendizaje basado en las metodologías activas. Ocho estudiantes de maestría o doctorado participaron en esta disciplina y como parte de las actividades cada uno de ellos desarrolló una práctica pedagógica con alumnos de la Enseñanza Básica o Superior, basadas en metodologías activas y con el uso de las TDIC. Como producto de esta experiencia cada estudiante produjo un texto reflexivo y una narrativa digital, representando el proceso de aprendizaje a lo largo de la disciplina. Los resultados del trabajo posibilitaron entender las diferentes concepciones sobre metodologías activas, así como analizar las potencialidades de esas metodologías para uso en diferentes niveles de enseñanza.

Palabras clave: Práctica pedagógica. Aprendizaje. Tecnología educativa.

\section{Introdução}

O intenso uso social das mídias e Tecnologias Digitais de Informação e Comunicação (TDIC), sobretudo pela portabilidade dos dispositivos móveis com conexão sem fio à internet (TMSF), em todo tempo e lugar, para acessar recursos, aplicativos e serviços oferecidos pela web, evidencia a convergência entre os espaços virtual e físico no cotidiano (JENKINS, 2008) e a onipresença das TDIC com a própria vida (LEMOS, 2004).

A convivência nos espaços híbridos multimodais da hiperconexão provoca mudanças nos modos de interagir, representar o pensamento, expressar emoções, produzir e compartilhar informações e conhecimentos, assim como aporta novos elementos à aprendizagem, podendo trazer novas 
contribuições e desafios aos processos educativos. As mudanças na sociedade e na cultura, advindas da disseminação das práticas sociais midiatizadas pelas TDIC, são de tal envergadura que suscitam estudos gerados em distintas áreas do conhecimento. Nesse sentido, Floridi (2015) trata da sociedade onlife; Iannone, Almeida e Valente (2016) enfatizam a escola na cultura digital e a cultura digital na escola; Santaella (2014) refere-se à aprendizagem ubíqua; Valente (2014) analisa o blended learning ou aprendizagem híbrida; e Almeida (2016) trata dos novos significados e sentidos sociais atribuídos à educação em tempos de ubiquidade.

Rodrigues (2001) concebe a educação como um processo integral de formação humana orientado para a liberdade, a solidariedade, a autonomia, a ética, o reconhecimento da individualidade do outro e a responsabilidade, com vistas à coexistência no mundo da cultura. Nesse contexto, faz-se necessário ressignificar o próprio conceito de educação e seus modos de fazer diante da emergência da cultura digital, caracterizada pela relação ubíqua com as TDIC e o conhecimento.

A educação que se desenvolve imbricada com a cultura encontra-se pressionada pelas práticas sociais típicas da cultura digital, caracterizadas pela participação em redes sociais virtuais da web, como Facebook, Instagram e Twitter. As redes potencializam a interação independente de hierarquias, a convivência com a abundância de informações disponíveis em distintas fontes - nem sempre confiáveis —, o estabelecimento de relações entre informações, a produção, o compartilhamento e a publicação de novas informações, a manifestação de opiniões para apoiar ideias, contradizer e explicitar valores de acordo com a ética que orienta as relações do sujeito com os outros e mobilizar pessoas para uma ação comum, em busca de atingir objetivos acordados socialmente.

Destaca-se como um dos desafios à educação o repensar sobre novas propostas educativas que superem a instrução ditada pelo livro didático, centrada no dizer do professor e na passividade do aluno. É importante considerar as práticas sociais inerentes à cultura digital, marcadas pela participação, criação, invenção, abertura dos limites espaciais e temporais da sala de aula e dos espaços formais de educação, integrando distintos espaços 
de produção do saber, contextos e culturas, acontecimentos do cotidiano e conhecimentos de distintas naturezas. A exploração dessas características e marcas demanda reconsiderar o currículo e as metodologias que colocam o aluno no centro do processo educativo e focam a aprendizagem ativa.

Diante disso, este texto tem o objetivo de conceituar metodologia e aprendizagem ativas, bem como identificar pontos de convergência entre os dois conceitos, apresentar distintos modos de trabalhar com metodologias ativas em diferentes níveis de ensino e provocar uma reflexão crítica sobre suas contribuições e limites quando as metodologias se desenvolvem com a midiatização das TDIC.

Este artigo foi realizado a partir de atividades desenvolvidas na disciplina Currículo, Tecnologias, Aprendizagem e os Desafios à Educação na Cultura Digital, ministrada durante o segundo semestre de 2016, no Programa de Pós-graduação em Educação: Currículo, da PUC-SP. Essa disciplina tinha como objetivo desenvolver práticas que explorassem o uso das TDIC e estudar as contribuições e limites que tais práticas oferecem ao desenvolvimento do currículo e à aprendizagem baseada nas metodologias ativas. Ela foi desenvolvida com base nas metodologias ativas, especialmente, a abordagem da sala de aula invertida, a partir da qual os estudantes de mestrado e doutorado realizaram práticas pedagógicas na educação básica ou superior usando as TDIC, baseadas em metodologias ativas, atuando diretamente no seu desenvolvimento ou em colaboração com outros professores. Como produto dessa experiência, cada estudante produziu um texto reflexivo e uma narrativa digital representando o processo de aprendizagem ao longo da disciplina.

\section{A metodologia de trabalho usada na disciplina}

A disciplina contou com oito estudantes, sendo dois do mestrado e seis do doutorado. Inicialmente, foi apresentada a proposta a ser realizada ao longo do semestre, e, aos estudantes, foi sugerida a leitura do artigo intitulado Políticas de tecnologia na educação brasileira: histórico, 
lições aprendidas e recomendações (ALMEIDA; VALENTE, 2016), o qual desenha um panorama histórico de programas e políticas de implantação das TDIC na educação de diferentes países e, mais especificamente, do Brasil. O objetivo dessa leitura foi discutir com os participantes o que já tinha sido realizado em termos do uso das tecnologias na educação, além de eles poderem conhecer o desenvolvimento histórico das diversas ações implantadas no Brasil.

O próximo passo na disciplina foi estudar as metodologias ativas de aprendizagem. Para tanto, os estudantes procuraram, em bases de dados científicas de livre acesso, artigos sobre esse tema e identificaram elementos que caracterizam as metodologias e a aprendizagem ativas. Esse estudo gerou uma importante discussão sobre o significado de metodologia e aprendizagem ativas, cujo resultado será abordado nas próximas seções.

Com base nestes estudos, os estudantes passaram a definir o tipo de prática pedagógica que iriam desenvolver ou acompanhar. Esta prática deveria usar as TDIC e ser aplicada por meio de alguma estratégia baseada em metodologias ativas. O trabalho deveria ser realizado individualmente e o estudante deveria registrar como as TDIC estavam sendo utilizadas, bem como o tipo de abordagem pedagógica e sua relação com as atividades curriculares. Esses registros deveriam ser empregados na elaboração de uma narrativa digital e servir para o desenvolvimento de um texto reflexivo sobre o que essa experiência significou em termos de aprendizagem ao longo do semestre.

À medida que os estudantes escolheram as práticas que seriam estudadas, elas foram discutidas em classe, o que serviu de base para a definição do que foi denominado "protocolo de investigação", instrumento orientador do estudo a ser elaborado. Esse protocolo foi definido com a colaboração dos estudantes, prevendo:

a) Descrição da atividade e respectivos participantes (local, população-alvo, papel do professor, materiais de apoio em uso), abordagem pedagógica explorada e atividades realizadas. 
b) Papel das TDIC e como elas estavam sendo utilizadas nessa prática.

c) Justificativa para a metodologia ativa usada e como ela estava sendo implantada nessa prática.

d) Conteúdos trabalhados (por exemplo, arte, matemática, ciências).

e) Integração entre tecnologias e conteúdos curriculares.

As práticas desenvolvidas foram individuais, sendo que cada estudante podia escolher o que estudar, de acordo com situações relacionadas com seu tema de pesquisa de mestrado ou doutorado ou com o que já desenvolvia em sua atividade profissional. Alguns temas propostos foram: acompanhar e analisar o processo de metodologia ativa desenvolvido por um aluno do curso de Agronomia da Universidade Estadual Paulista "Júlio de Mesquita Filho" (Unesp), campus Registro, no projeto de extensão universitária FertBike; estudo do Projeto Teatro, desenvolvido com alunos do sexto ano de uma escola estadual; acompanhamento e análise de alunos do quarto semestre do curso de Pedagogia, na disciplina Multiculturalismo, desenvolvendo uma atividade de mapeamento do que de cultural existe no bairro em que vive; e desenvolvimento e estudo de uma prática pedagógica realizada com alunos do primeiro ano do ensino médio de um colégio particular de São Paulo, utilizando metodologias ativas, como sala de aula invertida e pedagogia por investigação, que os auxiliaram nos estudos sobre a produção do espaço urbano.

Em relação ao último tema, os alunos desenvolveram a análise dos objetos de conhecimento planejados a partir do jogo digital City Rain $^{1}$, potencializando uma visão holística de planejamento urbano, bem como oferecendo importantes reflexões na tomada de decisão sobre aspectos inerentes ao espaço urbano em escala local. Nesse último caso, para identificação dos espaços, foi utilizado o Google Earth, tendo sido parte das tarefas realizada fora da sala de aula, enquanto em sala de

1 City Rain é um jogo brasileiro produzido com a tecnologia Microsoft XNA, que mistura os clássicos Sin City e Tetris, em uma temática de sustentabilidade (CITY RAIN, 2017). 
aula foi discutida a produção dos alunos. Nessa prática, trabalharam dois estudantes da disciplina, sendo que um desenvolveu o trabalho em sala de aula e o outro auxiliou na prática pedagógica por meio de atividades online. Dela, originaram-se duas narrativas, uma usando o próprio Google Earth e o outra realizada na forma de um hiperlink usando o software WiX.

Durante as aulas, foram discutidos temas ou informações trazidas do desenvolvimento das práticas que os alunos realizavam ou acompanhavam, em colaboração com os respectivos professores ou profissionais envolvidos, bem como artigos sugeridos pelos professores para dar suporte ao trabalho prático. Foram convidados dois pesquisadores para realizar palestras sobre seus trabalhos, cujos temas eram pertinentes ao que estava sendo tratado na disciplina.

À medida que as práticas ocorriam, os estudantes de mestrado ou doutorado apresentavam, de forma oral e/ou com suporte de material imagético, as informações que eram coletadas, cujo compartilhamento e reflexão no coletivo do grupo provocavam o olhar do autor sobre aspectos até então obscuros, ao mesmo tempo em que faziam os colegas repensarem sobre as próprias experiências. Essas apresentações serviram como sementes das narrativas digitais que foram desenvolvidas e permitiram identificar os conteúdos encontrados pelos estudantes, geralmente sugerindo retomar certos aspectos das práticas, de modo que pudessem entender melhor o que estava sendo realizado.

A maioria das aulas foi presencial e a disciplina contou com o suporte da plataforma Moodle, usada tanto para a organização da agenda de trabalho e repositório dos materiais de referência e da produção dos estudantes quanto para a realização de atividades síncronas e assíncronas on-line.

Nas próximas seções, discutem-se os resultados do estudo sobre metodologias ativas e aprendizagem ativa, como também algumas narrativas produzidas pelos estudantes da disciplina, procurando identificar as questões relacionadas ao currículo subjacentes às práticas, bem como às metodologias ativas utilizadas. 


\section{Metodologias ativas ou aprendizagem ativa}

O levantamento de artigos sobre o tema "metodologias ativas", que os estudantes realizaram, suscitou importantes discussões acerca de dois tópicos: a terminologia mais adequada - metodologia ou aprendizagem ativa - e as diferentes estratégias discutidas na literatura que, em geral, deixam de lado situações que também poderiam ser caracterizadas como metodologias ativas.

A maior parte da literatura brasileira trata as metodologias ativas como estratégias pedagógicas que colocam o foco do processo de ensino e aprendizagem no aprendiz, contrastando com a abordagem pedagógica do ensino tradicional, centrada no professor, que transmite informação aos alunos. $\mathrm{O}$ fato de elas serem caracterizadas como ativas está relacionado com a aplicação de práticas pedagógicas para envolver os alunos, engajá-los em atividades práticas, nas quais eles são protagonistas da sua aprendizagem. Assim, as metodologias ativas procuram criar situações de aprendizagem em que os aprendizes fazem coisas, colocam conhecimentos em ação, pensam e conceituam o que fazem, constroem conhecimentos sobre os conteúdos envolvidos nas atividades que realizam, bem como desenvolvem estratégias cognitivas, capacidade crítica e reflexão sobre suas práticas, fornecem e recebem feedback, aprendem a interagir com colegas e professor e exploram atitudes e valores pessoais e sociais (BERBEL, 2011; MORAN, 2015; PINTO et al., 2013).

Por outro lado, a literatura também tem usado o termo "aprendizagem ativa" para caracterizar situações de aprendizagem em que o aluno é ativo. Isso acontece uma vez que, em estudos e artigos na língua inglesa, essas situações são denominadas active learning (BELL; KAHRHOFF, 2006), o que tem sido literalmente traduzido como "aprendizagem ativa". Por exemplo, na revisão das pesquisas sobre uso da aprendizagem ativa, a terminologia "active learning" era utilizada desde 1991; por exemplo: "Active learning is generally defined as any instructional method that engages students in the learning process. In short, active learning requires 
students to do meaningful learning activities and think about what they are doing" (BONWELL; EISON, 1991 apud PRINCE, 2004, p. 223).

Durante as discussões, foi possível esclarecer que o termo "aprendizagem ativa" trata-se de uma redundância, em vista do que se conhece hoje sobre o processo de aprendizagem, especialmente sobre o funcionamento do cérebro. Independentemente de como se entende a aprendizagem, ela acontece em função da ação do sujeito, em interação com o meio. Quer ela se restrinja à memorização de informação, quer seja mais complexa, envolvendo a construção de conhecimento, o aprendiz tem que ser ativo, realizando atividades mentais, para que essa aprendizagem aconteça. Assim, não é possível entender que um indivíduo aprenda alguma coisa sem ser ativo. Nesse sentido, o termo "metodologias ativas" parece ser mais adequado para caracterizar situações criadas pelo professor com a intenção de que o aprendiz tenha um papel mais ativo no seu processo de ensino e aprendizagem.

Outro termo muito comum na literatura brasileira é "metodologias ativas de aprendizagem" (BARBOSA; MOURA, 2013; SOUZA et al., 2015; UVINHA; PEREIRA, 2010), que também é inadequado, considerando que o foco ainda está em tornar a aprendizagem ativa. $\mathrm{Na}$ verdade, as metodologias ativas são estratégias pedagógicas para criar oportunidades de ensino nas quais os alunos passam a ter um comportamento mais ativo, envolvendo-os de modo que eles sejam mais engajados, realizando atividades que possam auxiliar o estabelecimento de relações com o contexto, o desenvolvimento de estratégias cognitivas e o processo de construção de conhecimento.

O segundo tópico discutido durante as aulas foi a questão das diferentes estratégias de metodologias ativas. Tradicionalmente, tais metodologias têm sido implementadas por meio de estratégias como aprendizagem baseada em projetos (Project Based Learning - PBL), aprendizagem por meio de jogos (Game Based Learning - GBL), método do caso ou discussão e solução de casos (teaching case) e aprendizagem em equipe (Team-Based Learning - TBL). Mais recentemente, com a possibilidade de uso das TDIC em sala de aula, foram criadas condições 
para o desenvolvimento de metodologias ativas combinando atividades realizadas online por meio dessas tecnologias e atividades presenciais, conhecidas como blended learning ou ensino híbrido (STAKER; HORN, 2012).

Christensen, Horn e Staker (2013, p. 3) são autores que se dedicam a estudar a inovação nas organizações educativas e criaram uma classificação para as diferentes modalidades de ensino híbrido:

[...] os modelos de Rotação por Estações, Laboratório Rotacional e Sala de Aula Invertida seguem o modelo de inovações híbridas sustentadas. Eles incorporam as principais características tanto da sala de aula tradicional quanto do ensino online. Os modelos Flex, A La Carte, Virtual Enriquecido e de Rotação Individual, por outro lado, estão se desenvolvendo de modo mais disruptivo em relação ao sistema tradicional.

Embora essas sejam as metodologias ativas mais conhecidas e implantadas com maior frequência nas práticas educacionais usando as TDIC, existem outras que também criam condições para que os alunos sejam mais ativos e engajados nos processos de ensino e aprendizagem, como, por exemplo, a aprendizagem baseada na investigação. Essa metodologia foi utilizada em um projeto de pesquisa que usou os laptops educacionais na modalidade "um computador por aluno", realizado com alunos do primeiro ao nono ano do ensino fundamental de diversas escolas públicas, de modo que pudessem fazer ciência, em vez de estudar ciências (VALENTE; BARANAUSKAS; MARTINS, 2014). Ainda, a metodologia da problematização (BERBEL, 1998), baseada nas propostas de Freire (BERBEL, 1999), foi desenvolvida com alunos do nono ano do ensino fundamental, usando as TDIC para estudar a problematização das tecnologias na construção de um conhecimento diferenciado para o ensino e a aprendizagem de ciências (DARRONQUI, 2013).

A tentativa de envolver os aprendizes, de modo que possam ser mais ativos no processo de aprendizagem, não é nova. Por exemplo, Anastasiou e Alves (2004) descrevem cerca de 20 estratégias de 
"ensinagem" que preveem a participação ativa dos alunos, como, por exemplo, aula expositiva dialogada, criação de portfólios, elaboração de mapas conceituais etc. Esses autores não mencionam o uso das TDIC no desenvolvimento dessas metodologias, embora isso possa acontecer com praticamente todas elas. Assim, é preciso ampliar os horizontes quanto ao uso das metodologias ativas por meio das tecnologias digitais e não se ater ao que está em "moda" na atualidade.

Foi justamente o que se quis que os estudantes entendessem com o desenvolvimento da disciplina ministrada. Assim, além dos estudos de artigos e palestras de pesquisadores da área, os participantes tiveram que acompanhar ou desenvolver uma prática pedagógica com base nas metodologias ativas e no uso das TDIC. O registro do processo de aprendizagem realizado ao longo do semestre foi apresentado por meio de uma narrativa digital, que cada estudante construiu, usando recursos tecnológicos com os quais sentiam ter mais familiaridade ou que estavam interessados em aprender.

\section{Análise das narrativas digitais quanto às práticas das metodologias ativas estudadas}

Embora cada estudante tenha produzido uma narrativa, por questão de espaço, serão analisadas somente três delas, que atendem aos objetivos deste texto no que tange aos estudos sobre metodologias ativas em distintas situações e níveis de ensino: a narrativa desenvolvida a partir do trabalho com alunos universitários do projeto de extensão universitária FertBike, a narrativa produzida a partir do trabalho com alunos de uma escola pública e outra desenvolvida a partir do trabalho com alunos de um colégio particular. Para efeito da análise da narrativa, será considerada somente a prática pedagógica desenvolvida com base nas metodologias ativas usando as TDIC. 


\section{Prática pedagógica com alunos do projeto FertBike}

A mestranda que desenvolveu esta prática tem formação em Serviço Social e desenvolve sua pesquisa de mestrado nessa área. Seu interesse na disciplina era aprofundar o conhecimento acerca do uso de tecnologias na formação de alunos de Serviço Social a distância.

A prática pedagógica baseada em metodologias ativas desenvolvida teve como objetivo acompanhar e analisar o processo de aprendizagem de um aluno do curso de Agronomia da Unesp, campus Registro, no projeto de extensão universitária FertBike, que tem o apoio da PróReitoria de Extensão Universitária da universidade citada. O FertBike tem por finalidade sensibilizar o pequeno produtor rural sobre a importância da realização e avaliação da fertilidade do solo, iniciando pela correta análise de amostras do solo e a real utilização do laudo de recomendação de calagem e adubação. Além disso, esse projeto é desenvolvido por alunos usando a bicicleta como meio de transporte, a fim de incentivá-los a realizar exercícios físicos e, com as visitas ao campo, tomar conhecimento da realidade do produtor e do entorno em que está inserido.

O aluno, com os demais colegas do grupo, vai até a propriedade para conhecer o produtor e verificar se ele aceita participar do trabalho a ser realizado. O material do solo é coletado e o local de coleta é registrado via sistema de posicionamento global (GPS). Esse material é enviado ao laboratório da faculdade, no qual é analisado e interpretado. Com base nos resultados, são produzidas as recomendações técnicas de adubação necessárias para aquela propriedade, levando em consideração as condições financeiras do produtor. Com essas recomendações, os alunos retornam à propriedade para entregá-las ao produtor e explicar a forma como aplicá-las para ter bons resultados.

A partir das leituras realizadas, a mestranda identificou que as ações desenvolvidas pelos alunos podem ser fundamentadas na aprendizagem baseada na investigação, o que pode ser justificado a partir da leitura de diversas obras que tratam desse tema, como a de Vieira (2012), o material do Centro de Formação Pedagógica (CENFOP, 2011) e 
capítulos do livro ABInv - aprendizagem baseada na investigação (VALENTE; BARANAUSKAS; MARTINS, 2014).

A partir dessa experiência, a estudante fez a seguinte reflexão, que consta em sua narrativa:

Eu particularmente não tinha nenhuma aproximação com os conceitos de Metodologia e Aprendizagem ativa, deste modo, realizar a busca por definições foi bastante desafiador.

No entanto, descobri que estes conceitos estavam mais perto da minha realidade, do que eu imagina, sendo que, fiz uma inter-relação com o conceito socioeducativo, muito utilizado no Serviço Social. Já que o assistente social também usa de práticas educativas para trabalhar a emancipação dos usuários que atende.

É interessante notar que a mestranda pôde fazer essa relação com sua área de formação, mencionando que, também no Serviço Social, as metodologias ativas são utilizadas, no sentido de criar situações de engajamento e emancipação nas atividades socioeducativas.

\section{Prática pedagógica com alunos de uma escola estadual}

A doutoranda do Programa de Pós-graduação em Educação: Currículo atua como professora de História em uma escola estadual situada no município de Santo André, Região Metropolitana de São Paulo. Durante as aulas, mencionou que estava preocupada com a indisciplina, apatia e falta de paciência dos alunos para ouvir os professores nas aulas e vislumbrou o potencial das metodologias ativas articuladas com o uso da internet para minimizar esses problemas no trabalho com conteúdos curriculares por meio de projetos temáticos de investigação. Como professora da turma, a estudante propôs aos alunos do sexto ano o desenvolvimento de projetos, que, segundo sua narrativa, tinha como objetivo "aprofundar conhecimentos oriundos da Filosofia, História, Arte e da Língua 
Portuguesa", por meio da pesquisa e criação de peças teatrais centradas nos mitos gregos.

Os projetos foram desenvolvidos em grupos de alunos que deveriam usar as TDIC para a comunicação e colaboração com seus pares, a busca e organização de informações sobre os mitos, a criação do cenário de uma peça teatral e a elaboração de uma narrativa digital sobre a peça. O projeto foi iniciado pelos grupos com uma busca de informações na internet sobre os mitos gregos, cujas histórias eram analisadas, com vistas a identificar se seria viável encenar uma peça sobre elas e se o tema se encontrava articulado com os conteúdos em foco nas aulas da disciplina. Caixa de Pandora, Minotauro, Narciso, Reia e Cronos, entre outros, foram temas escolhidos pelos alunos.

Em seguida, os alunos criaram os cenários, figurinos e diálogos, por meio de processos dialógicos e colaborativos, em que as discussões entre os alunos e com a professora e a orientação sobre as dificuldades encontradas ocorriam via Facebook, telefone celular e em sala de aula.

No decorrer do trabalho, a colaboração expandiu-se com o envolvimento de duas ex-alunas da escola, ligadas à Companhia de Teatro Solas do Vento, que fizeram uma palestra e sugeriram outras fontes de informações e de materiais possíveis de serem usados no teatro, salientando que vestimentas, adereços e modos de evolução das cenas também constituem tecnologias. Assim, os cenários foram montados para compor a peça, que passou por um período de ensaios, quando a professora questionava os grupos e orientava os ajustes e os alunos refletiam sobre as próprias produções e atuação e propunham reformulações para chegar a um produto - peça teatral — com cenários coesos e articulados.

Os alunos também elaboraram narrativas digitais multimodais sobre o processo de criação das peças, os sons escolhidos, as imagens selecionadas e o papel assumido por cada um. É importante salientar a articulação entre a mitologia, a realidade atual e as tecnologias, como pode ser identificado na narrativa sobre o Minotauro e Teseu, que, no início, apresenta em texto e imagem a história desses mitos na Grécia Antiga; em seguida, registra a intenção de criar uma peça que articule o drama 
com o humor e seja adequada ao público infantojuvenil. Assim, a peça foi ambientada em uma cidade "mais moderna" nas vestes dos personagens e presença de tecnologias, mostrando o uso de telefones celulares e GPS, com projeção de imagens inseridas nos cenários.

Todas as peças criadas foram apresentadas na sala de leitura da escola, quando se fortaleceu o protagonismo dos grupos e foi feita uma votação para escolha das peças preferidas, que foram apresentadas na Biblioteca Cecília Meireles, do município de Santo André.

Refletindo sobre a prática realizada, a doutoranda menciona em sua narrativa o "esforço, a dedicação e o entusiasmo dos alunos", porém ressalta alguns problemas com as tecnologias em uso, "como o PowerPoint que não funcionou em alguns momentos e a falta do som em algumas etapas, o que denota a falta de preparo da escola". A doutoranda registra, também, aspectos relevantes sobre a aprendizagem:

Em se tratando da construção dos saberes metodológicos, observou-se que os alunos aprenderam a planejar as suas ações, a fazerem pesquisas, a desenvolverem o espírito colaborativo e se sentiram protagonistas do seu aprendizado.

Quanto ao saber mais teórico, percebi que os alunos, no geral, conseguiram, não só identificar os valores éticos contidos nas cenas, mas a fazerem relações com os teores vistos na aula, na atividade e nas situações cotidianas.

O fato dos alunos usufruírem de alguma liberdade, fez com que houvesse a necessidade de um acompanhamento mais incisivo do professor durante a execução da tarefa para que eles não se dispersassem. Nesse sentido, a impressão é que a metodologia ativa demanda maior esforço dos professores na educação básica visto que o prof. necessita lidar com a eventual falta de conhecimentos prévios teóricos e metodológicos dos alunos.

Os projetos desenvolvidos pelos alunos revelaram a criação de um contexto de aprendizagem baseado na investigação, que caracteriza uma metodologia ativa, conforme a intenção explícita da professora. Ela desafiou os alunos a criarem situações, com vistas a selecionar e 
inter-relacionar informações, construir e expressar o conhecimento e os sentimentos despertados pela história antiga articulada com a realidade atual e o imaginário. Tratou-se de uma experiência autêntica de aprendizagem, na qual os alunos engajaram-se, colaboraram entre si, exercitaram a autonomia, a criatividade, a criticidade, a responsabilidade e o respeito, questionaram o passado e interpretaram o presente, tomando os mitos e os acontecimentos em diferentes formas e sentidos, atribuindo novos significados, representados por meio da linguagem teatral, integrada com a multimodalidade e a hipertextualidade.

\section{Prática pedagógica com alunos de colégio particular}

O estudante de doutorado desenvolveu seu mestrado no Programa de Estudos Pós-Graduados em Geografia da PUC-SP, na linha de pesquisa Ensino de Geografia, articulando pesquisas nas áreas de educação geográfica e geotecnologias, como Google Earth, para alunos do ensino fundamental II anos finais e ensino médio. Ele é professor de Geografia para o ensino fundamental II em uma escola pública, e do ensino médio em um colégio particular. Atualmente, desenvolve seu doutorado no Programa de Pós-graduação em Educação: Currículo e pesquisa o ensino de Geografia no contexto da educação na cultural digital, trabalhando com estudantes do ensino médio do colégio mediante metodologias ativas e TDIC, particularmente, o Google Earth e o Google Maps.

Para o desenvolvimento da prática pedagógica da disciplina, ele trabalhou em parceria com outro colega no desenvolvimento de situações de aprendizagem associadas a jogos digitais, como City Rain, realizadas com um grupo de alunos do colégio que se interessou em participar dessa atividade, conforme o planejamento pedagógico. Essa prática foi baseada na abordagem da sala de aula invertida e na aprendizagem por investigação, de modo que os alunos pudessem estudar o planejamento urbano e refletir sobre a tomada de decisão em aspectos relativos ao espaço urbano em escala local. 
$\mathrm{Na}$ sua narrativa, o doutorando menciona que seu conhecimento sobre metodologias ativas, até o início da disciplina, "estava consubstanciado em referências clássicas como Vygotsky e Dewey, mas era tênue quanto à aplicabilidade de situações de aprendizagem além de confusão teórica quanto às tipologias de metodologias ativas". Ele tinha participado de uma palestra sobre ensino híbrido e possibilidades de aprendizagem ativa, relatando:

[...] saí com muitas ideias do ponto de vista da criação de situação de aprendizagem ativa, porém a fala do palestrante me pareceu extremamente dicotômica em relação a educação tradicional, desconstruindo aspectos pedagógicos essenciais desse modelo e realizando críticas generalizantes apontando que a melhora da educação está atrelada somente com a adoção de metodologias ativas auxiliadas por TDIC.

Durante o desenvolvimento da disciplina, além das leituras e atividades previstas, ele teve a oportunidade de participar de palestras sobre produtos na área de educação associada com robótica e programação. Como produto dessas experiências, relata em sua narrativa dois aspectos importantes:

[...] fiquei intrigado com os diversos interesses que instituições e empresas privadas possuem em divulgar excessivamente a melhoria da qualidade da aprendizagem através da combinação de metodologias ativas com tecnologias.

Ao longo do curso percebi uma defasagem teórica que me impediu de compreender adequadamente a ideia de procedimentos ativos na educação. A pouca experiência com os parâmetros do pensamento de Dewey, se apresentou como um obstáculo que dificultou ter clareza e evidência do pensamento desse autor nos procedimentos metodológicos ativos. Com certeza esse autor estará na próxima exploração bibliográfica a ser realizada como etapa dos procedimentos de minha tese de doutoramento. 
Realmente são aspectos preocupantes, em vista dos modismos costumeiramente criados e da apropriação por parte de empresas que apresentam produtos educacionais visando à implantação de metodologias ativas, porém sem considerar os contextos educacionais das escolas, bem como as questões relativas à formação de professores e às mudanças necessárias para a implantação dessas novas abordagens pedagógicas.

\section{Considerações finais}

A disciplina foi bastante importante para provocar o aprofundamento das concepções que ainda não estavam tão explícitas sobre as metodologias ativas, como a distinção entre metodologia e aprendizagem ativa e a variedade de metodologias consideradas ativas e que podem ser desenvolvidas usando TDIC. Além disso, mostraram-se as diferentes possibilidades de uso de estratégias relacionadas às metodologias ativas, em distintos níveis de ensino, desde o básico até o superior.

Em geral, os pós-graduandos matriculados não tinham muito conhecimento sobre as metodologias ativas, principalmente sobre como colocá-las em ação. O fato de terem que desenvolver ou acompanhar uma prática, articulado com os estudos sobre essas metodologias permitiu identificar concepções confusas em alguns artigos estudados, em propostas de produtos e soluções comerciais para a implantação dessas metodologias na educação.

Ainda se convive com modismos que acabam distanciando os educadores dessas propostas, embora os alunos expressem interesse por compreendê-las e se mostrem engajados, produtivos e reflexivos quando participam de atividades baseadas nessas metodologias. Como mencionou uma das doutorandas da disciplina, a implantação dessas práticas usando as TDIC pode ser iniciada em "um movimento 'de baixo para cima', em que se observa o incremento de uma educação que se horizontaliza e se expressa em múltiplas interações grupais e personalizadas". 


\section{Agradecimentos}

Aos alunos da disciplina, mestrandos e doutorandos, que colaboraram com este estudo por meio de sua participação nas atividades e da produção de suas narrativas: Álvaro Martins Fernandes Junior, Ana Léa Martins Lobo, Claudia Akiko Arakawa Watanabe, Cleide Maria dos Santos Munõz, Gerlane Romão Fonseca Perrier, Maria Eduarda de Lima Menezes, Thiago Souza Vale e Waldemar Jose Baptista de Carvalho. Ao $\mathrm{CNPq}$, pela bolsa produtividade em pesquisa dos autores José Armando Valente e Maria Elizabeth Bianconcini de Almeida.

\section{Referências}

ALMEIDA, M. E. B. Currículo e narrativas digitais em tempos de ubiquidade: criação e integração entre contextos de aprendizagem. Revista de Educação Pública, Cuiabá, v. 25, n. 59/2, p. 526-546, maio/ago. 2016. Disponível em: <http://periodicoscientificos.ufmt.br/ojs/index.php/educacaopublica/issue/view/260〉. Acesso em: 17 jan. 2017.

ALMEIDA, M. E. B.; VALENTE, J. A. Políticas de tecnologia na educação brasileira: histórico, lições aprendidas e recomendações. São Paulo: Centro de Inovação para a Educação Brasileira, 2016. (CIEB Estudos \#4). Disponível em: <http:// www.cieb.net.br/wp-content/uploads/2016/12/CIEB-Estudos-4-Politicas-deTecnologia-na-Educacao-Brasileira.pdf >. Acesso em: 2 mai. 2017.

ANASTASIOU, L. G. C.; ALVES, L. P. Estratégias de ensinagem. In: ANASTASIOU, L. G. C.; ALVES, L. P. (Org.). Processos de ensinagem na universidade: pressupostos para as estratégias de trabalho em aula. 3. ed. Joinville: Univille, 2004. p. 67-100.

BARBOSA, E. F.; MOURA, D. D. Metodologias ativas de aprendizagem na educação profissional e tecnológica. Boletim Técnico do Senac, Rio de Janeiro, v. 39, n. 2, p. 48-67, maio/ago. 2013. Disponível em: <http://www.bts.senac.br/index.php/ bts/article/view/349>. Acesso em: 2 mai. 2017. 
BELL, D.; KAHRHOFF, J. Active learning handbook. St. Louis: Webster University. 2006. Disponível em: <http://www.cgs.pitt.edu/sites/default/files/Doc6GetStarted_ActiveLearningHandbook.pdf $>$. Acesso em: 2 mai.. 2017.

BERBEL, N. A. N. A problematização e a aprendizagem baseada em problemas: diferentes termos ou diferentes caminhos? Interface - Comunicação, Saúde, Educação, São Paulo, v. 2, n. 2, p. 139-154, 1998. Disponível em: <http://www. scielo.br/pdf/icse/v2n2/08>. Acesso em: 3 mai. 2017.

BERBEL, N. A. N. A metodologia da problematização e os ensinamentos de Paulo Freire: uma relação mais que perfeita. In: BERBEL, N. A. N. (Org.). Metodologia da problematização: fundamentos e aplicações. Londrina: Eduel, 1999. p. 1-28.

BERBEL, N. A. N. As metodologias ativas e a promoção da autonomia de estudantes. Ciências Sociais e Humanas, Londrina, v. 32, n. 1, p. 25-40, jan./jun. 2011. Disponível em: <http://www.uel.br/revistas/uel/index.php/seminasoc/article/ view/10326>. Acesso em: 2 mai. 2017.

CENTRO DE FORMAÇÃO PEDAGÓGICA (CENFOP). O ensino de ciências por investigação. 2011. Disponível em: <https://cenfopciencias.files.wordpress. com/2011/07/apostila-ensino-por-investigac3a7c3a3o.pdf >. Acesso em: 20 out. 2016.

CHRISTENSEN, C.; HORN, M.; STAKER, H. Ensino híbrido: uma inovação disruptiva? Uma introdução à teoria dos híbridos. Maio de 2013. Disponível em: <http://porvir.org/wp-content/uploads/2014/08/PT_Is-K-12-blendedlearning-disruptive-Final.pdf $>$. Acesso em: 2 mai. 2017.

CITY RAIN. Wikipédia. Disponível em: <https://pt.wikipedia.org/wiki/City_ Rain>. Acesso em: 2 mai. 2017.

DARRONQUI, S. R. Do uso à mediação de tecnologias no ensino-aprendizagem de ciências: uma abordagem investigativa de prática educacional no ensino fundamental. 2013. 145 f. Dissertação (Mestrado Profissional em Formação Científica, Educacional e Tecnológica) - Universidade Tecnológica Federal do Paraná, Curitiba, 2013. 
FLORIDI, L. (Ed.). Onlife manifesto: being human in a hyperconnected era. London: Springer, 2015. Disponível em: <http://www.springer.com/us/ book/9783319040929>. Acesso em: 5 mai. 2017.

IANNONE, L. R.; ALMEIDA, M. E. B.; VALENTE, J. A. Pesquisa TIC Educação: da inclusão para a cultura digital. In: NÚCLEO DE INFORMAÇÃO E COORDENAÇÃO DO PONTO BR (Ed.). TIC Educação 2015: pesquisa sobre o uso das tecnologias de informação e comunicação nas escolas brasileiras. São Paulo: Comitê Gestor da Internet no Brasil, 2016. p. 55-67. Disponível em: <http://cetic.br/media/docs/ publicacoes/2/TIC_Edu_2015_LIVRO_ELETRONICO.pdf $\rangle$. Acesso em: 5 mai. 2017.

JENKINS, H. Cultura da convergência. São Paulo: Aleph, 2008.

LEMOS, A. Cibercultura e mobilidade: a era da conexão. Razón y Palabra, ano 9, n. 41, out./nov. 2004. Disponível em: <http://www.razonypalabra.org.mx/anteriores/n41/alemos.html>. Acesso em: 10 abr. 2017.

MORAN, J. M. Mudando a educação com metodologias ativas. In: SOUZA, C. A.; MORALES, O. E. T. (Org.). Convergências midiáticas, educação e cidadania: aproximações jovens, v. 2. Ponta Grossa: Foca Foto-PROEX/UEPG, 2015. (Coleção Mídias Contemporâneas). Disponível em: <http://www2.eca.usp.br/moran/wp-content/uploads/2013/12/mudando_moran.pdf >. Acesso em: 2 mai. 2017.

PINTO, S. et al. O Laboratório de Metodologias Inovadoras e sua pesquisa sobre o uso de metodologias ativas pelos cursos de licenciatura do UNISAL, Lorena: estendendo o conhecimento para além da sala de aula. Revista de Ciências da Educação, São Paulo, v. 2, n. 29, p. 67-79, jun./dez. 2013.

PRINCE, M. Does active learning work? A review of the research. Journal of Engineering Education, v. 93, n. 3, p. 223-231, 2004. Disponível em: <http:// www4.ncsu.edu/unity/lockers/users/f/felder/public/Papers/Prince_AL.pdf 〉. Acesso em: 2 mai. 2017. 
RODRIGUES, N. Educação: da formação humana à construção do sujeito ético. Educação \& Sociedade, Campinas, ano XXII, n. 76, p. 232-257, out. 2001. Disponível em: 〈http://www.scielo.br/pdf/es/v22n76/a13v2276.pdf〉. Acesso em: 15 fev. 2017.

SANTAELLA, L. A aprendizagem ubíqua na educação aberta. Revista Tempos e Espaços em Educação, São Cristóvão, v. 7, n. 14, p. 15-22, set./dez. 2014. Disponível em: <https://seer.ufs.br/index.php/revtee/article/view/3446/3010〉. Acesso em: 20 abr. 2017.

SOUZA, A. E. et al. Metodologias ativas de aprendizagem no ensino superior de tecnologia. In: CONGRESSO NACIONAL DE EDUCAÇÃO, 12., 2015, Curitiba. Anais... Curitiba: PUCPR, 2015. Disponível em: <http://educere.bruc.com.br/arquivo/pdf2015/16714_7546.pdf >. Acesso em: 3 mai. 2017.

STAKER, H.; HORN, M. B. Classifying K-12 blended learning. Mountain View: Innosight Institute, 2012. Disponível em: <http://www.christenseninstitute. org/wp-content/uploads/2013/04/Classifying-K-12-blended-learning.pdf > . Acesso em: 5 mai. 2017.

UVINHA, R. R.; PEREIRA, D. Metodologias ativas de aprendizagem no ensino de ciências humanas e sociais. ComCiência: Revista Eletrônica de Jornalismo Científico, 10 fev. 2010. Disponível em: <http://www.comciencia.br/comciencia/handler.ph p?section=8\&edicao=53\&id=673 $>$. Acesso em: 2 mai. 2017.

VALENTE, J. A. Blended learning e as mudanças no ensino superior: a proposta da sala de aula invertida. Educar em Revista, Curitiba, n. 4, p. 79-97, 2014. Disponível em: <http://www.scielo.br/pdf/er/nspe4/0101-4358-eresp-04-00079.pdf> Acesso em: 18 fev. 2017.

VALENTE, J. A.; BARANAUSKAS, M. C. C.; MARTINS, M. C. ABInv-aprendizagem baseada na investigação. Campinas: Unicamp/NIED, 2014. Disponível em: <http://www.nied.unicamp.br/?q=content/abinv-aprendizagem-baseada-na-investigação>. Acesso em: 8 abr. 2016. 
VIEIRA, F. A. C. Ensino por investigação e aprendizagem significativa crítica: análise fenomenológica do potencial de uma proposta de ensino. 2012. $144 \mathrm{f}$. Tese (Doutorado em Educação para a Ciência - Universidade Estadual Paulista, Bauru, Faculdade de Ciências, 2012. Disponível em: <http://hdl.handle. net/11449/102039>. Acesso em: 02 mai. 2017.

Recebido: 20/04/2017

Received: 04/20/2017

Aprovado: 25/05/2017 Approved: 05/25/2017 